\title{
PARAMETERS ON SUPPORT STRUCTURE DESIGN FOR METAL ADDITIVE MANUFACTURING
}

\author{
S. Weber ${ }^{1,2, \otimes}$, J. Montero ${ }^{1,2}$, M. Bleckmann ${ }^{2}$ and K. Paetzold ${ }^{1}$ \\ ${ }^{1}$ Bundeswehr University Munich, Germany, ${ }^{2}$ Bundeswehr Research Institute for Materials, Fuels and Lubricants, \\ Germany \\ s.weber@unibw.de
}

\begin{abstract}
The topic of support structure design in the Design for Additive Manufacturing (DfAM) field is not addressed with the same relevance as the topic of part design. Therefore, this contribution investigates parameters for both the manufacturing and support structure design for the Laser Powder Bed Fusion (L-PBF) process. Matrices for cause-effect-relations of manufacturing and design parameters on build properties as well as correlations of them are presented. Based on these, recommendations for actions for experimental procedures are derived following the Design of Experiments method.
\end{abstract}

Keywords: additive manufacturing, 3D printing, design for $x(D f X)$, powder bed fusion, support structure

\section{Introduction}

Over the last few years Additive Manufacturing (AM) strongly gained importance among manufacturing technologies (Schleifenbaum et al., 2019). Besides the consumer sector for thermoplastic filament printers, AM has its rise especially in Metal Additive Manufacturing. The technology and mindset in the field of AM developed over time from AM only to be used for Rapid Prototyping to the manufacturing of fully functional parts. Especially the spare part production benefits from the versatility of AM (Montero et al., 2019). The most common AM technology in industry is the Powder Bed Fusion (PBF) process. In 2019 this led to a more than $40 \%$ increase in sales volume of metal powder for the AM industry worldwide (Wohlers, 2019). This increasing interest in AM is also reflected by the many publications on part design for additive manufactured parts. Support structures have a high influence on the printing process, but a detailed investigation is lacking. Additionally there is a variety of different AM technologies and therefrom resulting different requirements on support structure design (Jiang et al., 2018) making it difficult to present generic rules. Therefore, parameters for the design of support structures are evaluated based on the requirements for PBF processes.

The consequence of a minor portion of research in the field of support structures is a lack of Design for Additive Manufacturing (DfAM) guidelines and rules of thumb that put their focus on support structures and not only on part design itself. This in turn leads to an insufficient understanding of support structure design and interpretation. If this knowledge about the usage of specific support structures is not present, the designed parts might not be manufacturable or support structure might be difficult to remove after printing. Automatic support generation is often integrated in pre-processing software but is most of the time poorly implemented at the moment. Therefore it can happen that 
support structure generated in this way is self-intersecting with the part or the cross sectional area is not large enough to ensure manufacturing without failure. Also automatic support is usually using block support only. This leads to a higher material consumption and increased post-processing time.

This article determines important manufacturing and design parameters for further investigation of support structure design based on existing literature and experiences from the authors. The effects of the parameters on build properties and the correlation effects of build properties against each other are shown in matrices. As a result of the parameter determination an experimental plan is derived. Therefore the scope of this paper is the presentation of a line of thought for a Design of Experiments on tree-like support structure design.

\section{State of the art}

Additive Manufacturing (AM) describes a manufacturing process for adding material layer by layer based on 3D model data to generate a new part (DIN, 2017; VDI, 2014). This can also be achieved by a transition from powder that is considered as a liquid to solid. The Term $3 D$ Printing is commonly, mostly in the private sector, used as a synonym to AM. Opposed to that are traditional (subtractive) manufacturing processes like milling or turning where material is removed from a semi-finished part.

\subsection{Laser powder bed fusion}

The Laser Powder Bed Fusion (L-PBF) process, depending on machine manufacturers also known as Selective Laser Melting (SLM®) by SLM Solutions ${ }^{\circledR}$ or Direct Metal Laser Sintering (DMLS ${ }^{\circledR}$ ) by EOS ${ }^{\circledR}$ is an additive manufacturing technique developed in the 1980s and belongs to the class of powder bed fusion processes (DIN, 2017). Common materials are polymer, metal and ceramic powders. For this study only metal powders are considered. A thin layer of metal powder is placed layer by layer on a build plate using a recoating device. After each layer a laser beam is used as an energy source to melt these metal powder particles on to each other, generating the component. The build plate lowers after each layer by a specific amount, usually in a range of $20 \mu \mathrm{m}$ to $50 \mu \mathrm{m}$, specifying the layer height. This process is repeated until the part is done. During manufacturing inert gas flows through the build chamber in order to cope with oxidation of the part and take away the emerging smoulder. It is beneficial to preheat the powder to minimize the temperature gradient between loose powder and the melting strip. The L-PBF process needs support structure on overhanging surfaces for process heat dissipation and to prevent the melting band from sinking into the powder bed. Overhanging structures are defined by Calignano (2014) as "a part of a component that is not supported during building, by solidified material or a substrate on the bottom side." In contradiction to metal L-PBF there is no need for support structure in polymer PBF processes, as the powder bed acts sufficiently as a mechanical fixation, because of the lower temperature gradient. On the other hand for metal powder, support structure is also needed for the mechanical fixation of the part on the build plate. Especially in overhanging regions thermally induced residual stresses lead to undesired local warping (Mercelis and Kruth, 2006) that can be reduced or prevented by the use of support structure. Common materials used in the metal L-PBF process are among others titanium and aluminium alloys as well as stainless steel. A schematic of the process is shown in Figure 1.

\subsection{Support structures in metal $A M$}

Support structure is a necessary element of part production using the L-PBF process. It is used to fix the part to the base plate and reduce thermal deformations. Another purpose of support structure is to support overhanging surfaces, which cannot be compensated by alternation of the build orientation. After printing is done, the support structure has to be removed by conventional manufacturing methods in a postprocessing step. An uneven and rough surface is the result. There are different types of support structure, which can, dependent on their design, be assigned to one or more additive manufacturing processes. Small wall thicknesses or diameters are for example better suited for L-PBF processes than for filament printing. These types contain, but are not limited to, those shown in Figure 2. Not shown is the so called LatticeSupport, consisting of repeated unit cells and are the scope of an article by Hussein et al. (2013) as well as Strano et al. (2013) or the Web-Support, which is arranged in the shape of a spider web. The used 
terminology for the types of support structure is not consistent in literature and industry. All support structures are named by the way they are designed. Block-Support for example is in the group of volume support as it is defined by a complete supported surface while Polyline-Support is defined only by edges of the part. Several design parameters for Block-support are investigated by Calignano (2014) and Zhang et al. (2018) for aluminium and titanium parts produced by L-PBF. Tree-like- and Bar-Support are defined by one starting point on the base plate and one ore multiple end points on the part as well as the diameters of each section, leading to the list of design parameters used in Figure 4. An alternative way for the design of support structures leading to Tree-like shapes is the use of thermal simulations (Bartsch et al., 2019) or topology optimization (Kuo et al., 2018). Problem with such approaches is the complexity to control the resulting support structure in respect to removability or support strength. Also at the current state these optimization problems are carried out only for two dimensional models. Furthermore, support structures can be classified by the way they are generated in primary and secondary structures. Primary support structures are designed together with the part resulting in one single model. The benefit of this approach is, that support structure and part design are strongly connected and can be adapted to each other's needs. Secondary support structures are added after the part design is completed. This is usually done in a specific 3D printing software for part orientation, support generation and slicing into layers. The benefit of secondary support is that it can be added by a third party during the print preparation. The most common software tool for print preparation in the field of metal additive manufacturing is Materialise Magics.

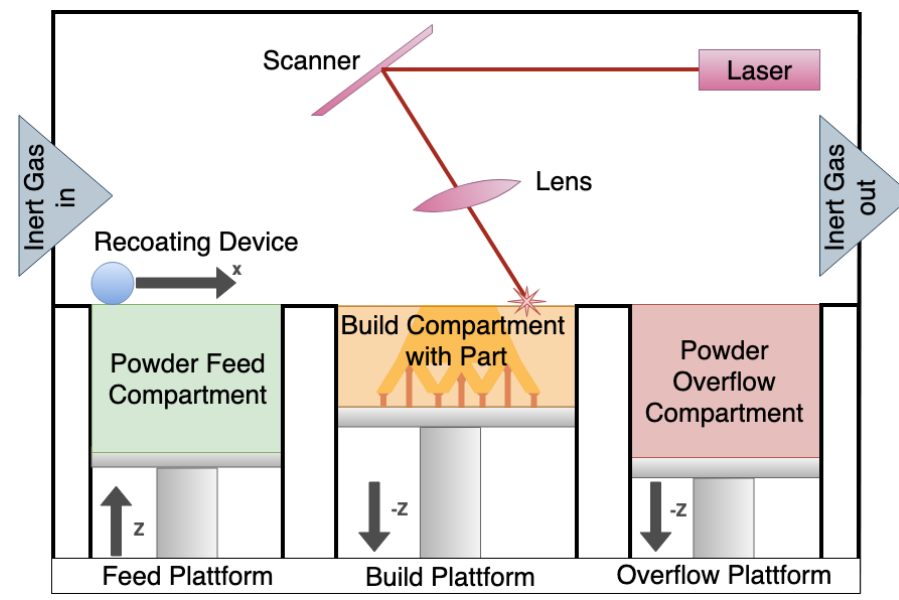

Figure 1. Schematic of the L-PBF process

\subsection{Current challenges in support structure design}

With metal additive manufacturing being used for customized parts and low-volume production, it becomes increasingly important to print the first time successfully (Gibson, 2017). One of the most common problems is the failure of the support structure during the process (Domagala, 2018). The part is then able to deform freely. As soon as the top surface of the part is no longer at level with the powder bed, the recoating device fails to apply new powder. The reason for failed support structure is that most of the time designers underestimate the importance of it. This is also shown by the use of secondary support that is, opposed to primary support, added after the part design in a late stage. Often residual stresses are also not calculated or estimated and therefore not considered in the design.

In order to print on the first try successfully, it is necessary to use the strong dependencies between part orientations, support structure and part design as a benefit. Designers then have the opportunity to add special connection points for support structure during part design that will not fail in manufacturing. Given the current lack of understanding of AM process characteristic described by Dordlofva and Törlind (2018), it is important to have designers, who are trained in Design for Additive Manufacturing (DfAM). In addition, DfAM guidelines have not reached maturity in terms of support structure design. In order to reduce the complexity in print preparation, attempts are being made for automatic support generation. Depending on the geometry of the part and its need for support structure, automatic algorithms tend to fail and create self-intersections. These challenges lead to the following research questions (RQ): 
RQ1: How must support structure be designed to achieve the best mechanical behaviour of the part?

RQ2: Which type of support structure should be used at which point?

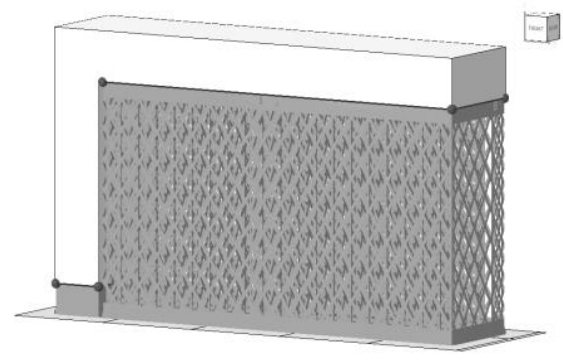

(a)

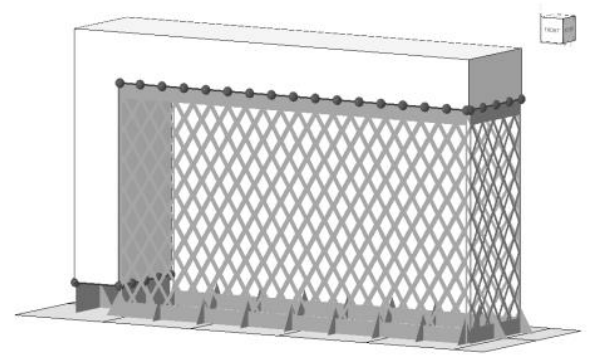

(c)

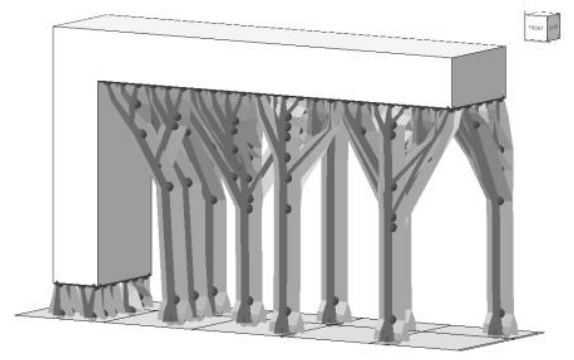

(b)

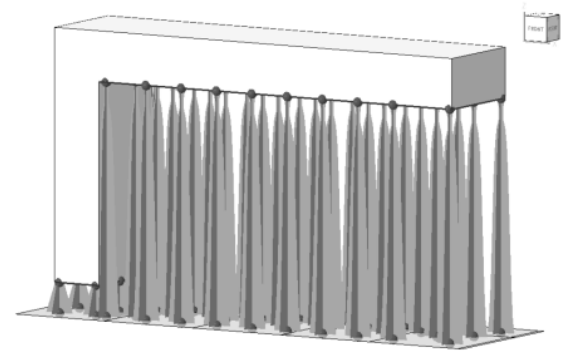

(d)

Figure 2. Types of support structure: Block-Support (a), Tree-like-Support (b), Polyline-Support (c) and Bar-Support (d)

\section{Method}

The following section will describe how important manufacturing and design parameters are determined and why Tree-like-Support is used for further investigations. Additionally the selected geometry for experimental and simulation studies is presented and discussed.

\subsection{Selection of Tree-like-Support}

Additive manufacturing is known for the possibility to design freely without any restrictions. This is not completely true for most of the manufacturing technologies. Besides other restrictions, in the powder bed fusion processes for metal additive manufacturing there is a need for support structure. Among the different types of support structure, Tree-like-Support gives the best flexibility in design. The stems can be placed on the build plate at each point in a specific radius around the top connecting points that results in the maximum possible overhang angle. Opposed to other types of support structure this gives the possibility to avoid contact of the stem with sections of the part that don't need any support. Another benefit is the low material consumption. While Block-Support fills a large proportion of the volume under the supported area, Tree-like-Support on the other hand needs only a high density of the branches in the top. The stems can have a rather large distance to each other. This smaller proportion of powder leads to a faster build rate. Polyline-Support in contrast can only support edges and is therefore not further investigated. On top of these benefits of Tree-like-Support over traditional support structures, it is worth mentioning that it is also the result of thermal and structural optimization studies performed by Bartsch et al. (2019). Hence, for this study the Tree-like-Support structures were selected for further investigation on their design.

\subsection{Determination of parameters}

Before the determination of design parameters, a closer look is taken on manufacturing parameters as they control the manufacturing process. Hence, they have a large influence on both, the part and the 
support. To rate this influence the effect of some manufacturing parameters on selected build properties is evaluated from literature. As in section 2.3 the aim is described as printing the first time right, reliability of the manufacturing process is important. To achieve this, the printability is the most important build property for support structure design. Not to mention the part strength as it is next to the part quality the overall goal of a successful print. The manufacturing parameters under investigation were selected because they are the most frequently adjusted parameters of the total changeable machine parameters. To determine the effect (increase, decrease or no effect) on build parameters due to the increase of one manufacturing parameter a literature study was performed. The results for minor variations of recommended parameters within a plausible range are shown in the matrix in Figure 3.

\begin{tabular}{|c|c|c|c|c|c|c|c|c|}
\hline & & 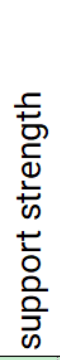 & 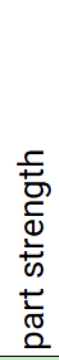 & 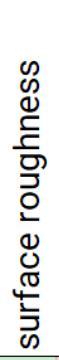 & 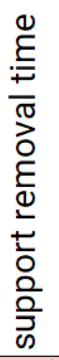 & 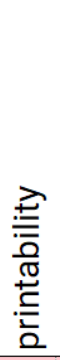 & 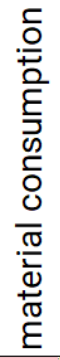 & 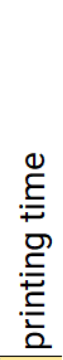 \\
\hline \multirow{9}{*}{ 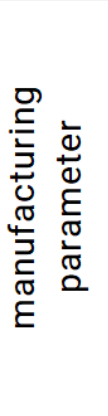 } & \multirow{9}{*}{$\begin{array}{l}\text { laser power } \\
\text { scanning speed } \\
\text { layer height } \\
\text { hatch spacing } \\
\text { hatch angle interval } \\
\text { baseplate temperature } \\
\text { build chamber temperature } \\
\text { gas flow improvement } \\
\text { layer skipping for supports }\end{array}$} & 个 & $\uparrow$ & $\Downarrow$ & त्र & y & त & $\Rightarrow$ \\
\hline & & $\Downarrow$ & $\Downarrow$ & $\uparrow$ & עل & עy & $\Rightarrow$ & $\Downarrow$ \\
\hline & & $\Rightarrow$ & $\Rightarrow$ & $\uparrow$ & $?$ & y & $?$ & $\downarrow$ \\
\hline & & त & 2 & श & $?$ & $?$ & $?$ & y \\
\hline & & 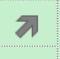 & $\pi$ & $?$ & $?$ & עy & $?$ & $\Rightarrow$ \\
\hline & & $\pi$ & $\pi$ & $y$ & $?$ & $\lambda$ & $?$ & $?$ \\
\hline & & $\pi$ & $\pi$ & עy & $?$ & त & $?$ & $?$ \\
\hline & & $\pi$ & 27 & עy & $?$ & $\pi$ & $\Rightarrow$ & $\Rightarrow$ \\
\hline & & $\Downarrow$ & $\Rightarrow$ & $\Rightarrow$ & $\Downarrow$ & $y$ & ? & \\
\hline
\end{tabular}

Figure 3. Matrix of effects on build properties caused by increase of machine parameter values

Arrows pointing upwards describe an increase of the build property resulting from an increase of the manufacturing parameter. Downwards pointing arrows respectively stand for a decrease. Arrows pointing to the right mean no effect. The background colours of the cells indicate whether the effect is seen as beneficial or unfavourable. For interactions where neither empirical results were present nor any literature was found, a question mark is placed in the cell. References for each cell are included in the figure in appendix A.

It can be seen that the two most influencing parameters are laser power and scanning speed. They each affect the build properties in an inverse manner. This is because of the energy input that is defined by power input per time and area, i.e., scanning speed is proportional inverse to laser power. Also interesting is the beneficial effect of baseplate and build chamber temperature on almost all of the build properties. It has to be mentioned that the matrix only gives an overview of the effects. For most of the manufacturing parameters, there are values (usually defined as a pre-set by the machine manufacturer) that result in good build properties. The scope of this matrix is for values around these pre-sets. Outside of this value region, the effect on build properties can even be contradictory. Also the used material can have a huge impact on the resulting effect. With a lower melting temperature for example less energy input is needed. Therefore, thermal gradients are less aggressive leading to lower residual stresses and improved printability.

Design parameters are values that need to be specified during part design or in pre-processing and are therefore selected based on parameters used in the CAD model of a supposed test sample. Every design of Tree-like-Support is subject to the seven parameters listed in the matrix. The effect for Treelike-Support structures on build properties is shown in Figure 4. The orientation of the arrows in the matrix is based on the authors' experiences from previous prints and has together with the cell 
background colour the same meaning as in Figure 3. Opposed to manufacturing parameters, the design parameters should primarily affect the support structure and therefrom the printability. They do not have an effect on part strength. Nevertheless the effect on surface roughness cannot be neglected. It can be seen that the diameters of the stems and branches as well as the number of branches affect more build properties than the other design parameters. Therefrom it is possible to derive the significance of each parameter for further studies.

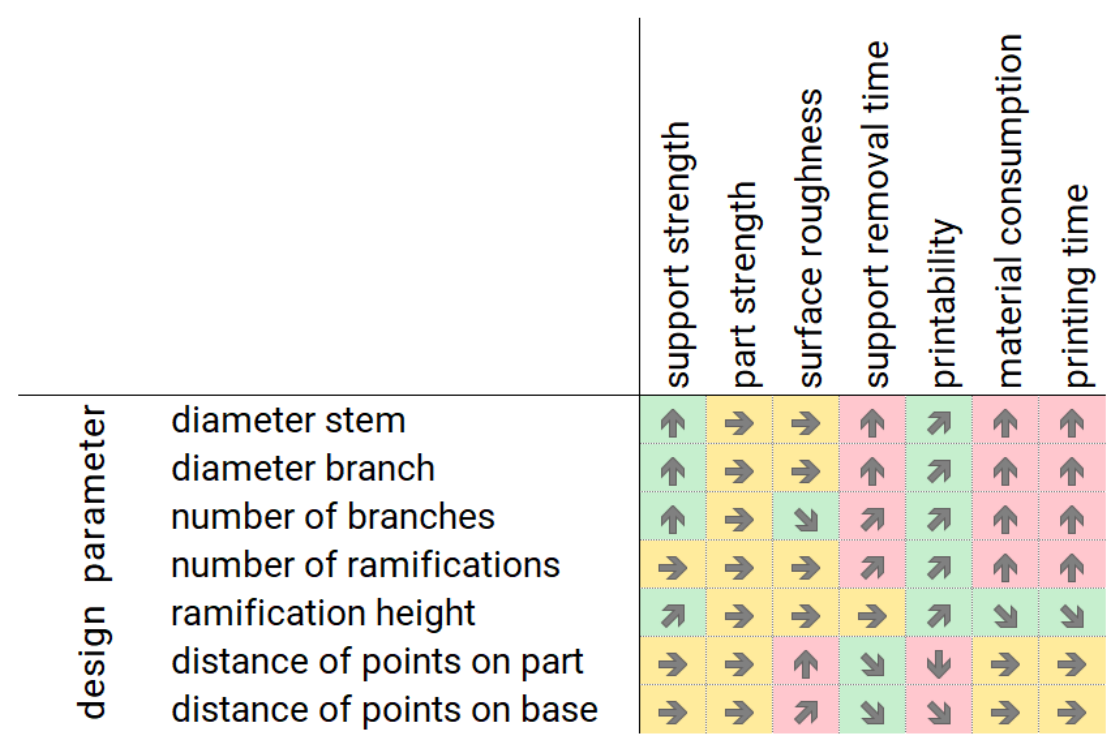

Figure 4. Matrix of effects on build properties caused by increase of design parameter values

In Figure 5 correlations between the build properties are shown. Each build property is compared against all the others and the effect on an increase of that specific property is displayed as an arrow. Because of the behaviour that sometimes one property has an effect to increase another one but not vice versa, the diagonal line does not function as a mirror axis. Additionally to the build properties, laser power and scanning speed are added to the matrix, because of their high correlation effects. The background of the cells is left white, because it cannot be determined for all cells whether an effect is seen as beneficial or not. The arrows indicate a potential but not inevitable correlation.

Furthermore, there is a high correlation between support strength and support removal time as well as printability. Both increase with a higher support strength. Another effect that stands out in the matrix is the correlation between material consumption and printing time. Higher material consumption means a larger area per layer that needs to be scanned. With consistent laser power and scanning speed the overall printing time is therefore longer. The effect of surface roughness on the parts and supports fatigue strength has to be pointed out in particular. A rough surface increases the probability of crack initiation under dynamic loads and therefrom increases the probability of part failure.

\section{Experimental procedures}

Using the determined parameters from the previous section, a plan for experimental procedures can be derived. The first set of tests has to be carried out to determine the important parameters for Tree-like support structure design and therefore verify the relations displayed in the matrix of Figure 4. As manufacturing parameters are affecting the support structure and the part, they are set to fixed values and considered as noise factors following the Design of Experiments (DoE) terminology. This leaves the seven independent design parameters as control factors (cf. DoE). Even though multiple responses (cf. DoE) can be measured with a single experiment, only one can be considered in the determination of the significance of parameters. Therefore support strength is selected as response for the experiments, because of the strong correlation between the support strength and the printability shown in Figure 5. Also support strength can be measured as continuous values opposed to the discrete 
behaviour of printability (failed or not) and is therefore better suited as response. The suggested experiments can be executed as tensile tests on a non-machined part with for example a diameter range between $0.1 \mathrm{~mm}$ and $1 \mathrm{~mm}$. Appropriate test values for the other design parameters are to be determined. The first set of experiments can be seen as a screening to reduce the amounts of parameters for investigations with full factorial designs in a later stage. For a fast screening the amount of levels (cf. DoE) for each factor is set to two. The lowest and highest applicable value. Considering all of these boundary conditions, the highly fractional factorial Taguchi Orthogonal Array L8 design is chosen. This leads to seven factors that need to be tested in eight runs of experiments. For determination of significant factors based on the results of the Taguchi Design a Pareto chart is suggested. It shows the effect values of statistically significant factors as bars crossing a reference line that is created based on a specified level of significance.

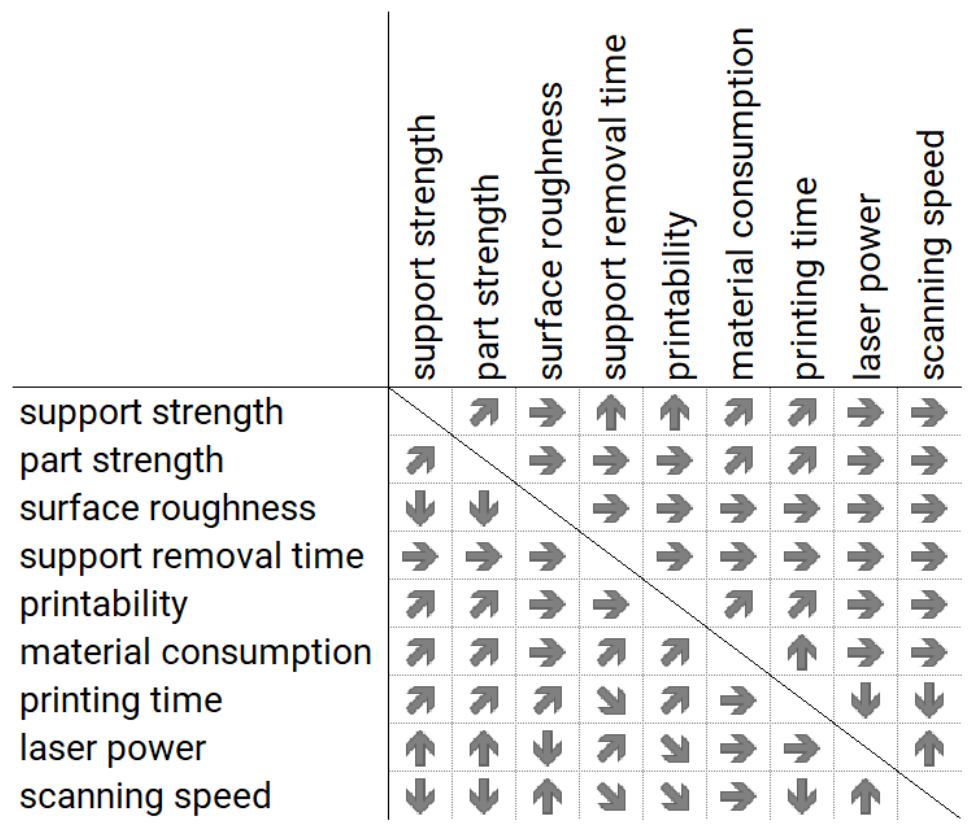

Figure 5. Matrix of build property correlation effects

Assuming the significant factors can be reduced as expected to the first three design parameters, which show a high impact on support strength in the matrix of Figure 4, a full factorial design needs to be conducted. For these experiments the amount of levels is set to three, in order to represent a possible quadratic behaviour of the interaction between factors and response. With the new boundary conditions of three factors with three levels, the full factorial design leads to 27 necessary experiments.

\section{Conclusion}

\subsection{Discussion}

The paper at hand is showing preliminary results of a study on design parameters for Tree-likeSupport and proposing a Design of Experiments for the determination of such parameters. Therefore it can be considered as the screening for relevant parameters of the design process. Additionally to the presented investigations, simulations with commercial software were carried out. Due to missing parameters for the thermal influence of the powder particles on the build process, the results do not match the physical tests perfectly and are therefore not included in this publication.

In Figure 6 an artefact is presented to verify some of the effects presented in the design parameter matrixes of section 3.2 and to show the necessity of this study. The test sample was designed as a cantilever to have a large overhanging surface and therefore resulting in a complex to build part that gives enough space for the design of different Tree-like-Supports. The dimensions are $45 \mathrm{~mm}$ in length, $10 \mathrm{~mm}$ depth and $5 \mathrm{~mm}$ thickness of the vertical and horizontal bars and a total height of 
$25 \mathrm{~mm}$. The Tree-like-Support was designed using a CAD-System with a diameter of the stems and branches of $0.4 \mathrm{~mm}$ and a ramification height of $5 \mathrm{~mm}$ measured from the overhanging surface. In Figure 6 can be seen that with an increasing length of the overhanging surface the deformation of the stems of the support structure also increases until the diameter is no longer sufficient for the material to withstand the stresses inside the stems. The result is the failure of the support during the build leading to severe warping at the end of the cantilever due to missing anchors. Additionally to the failed supports it is visible that the number of the branches is not sufficient if the roughness of the downward facing surface is of importance.

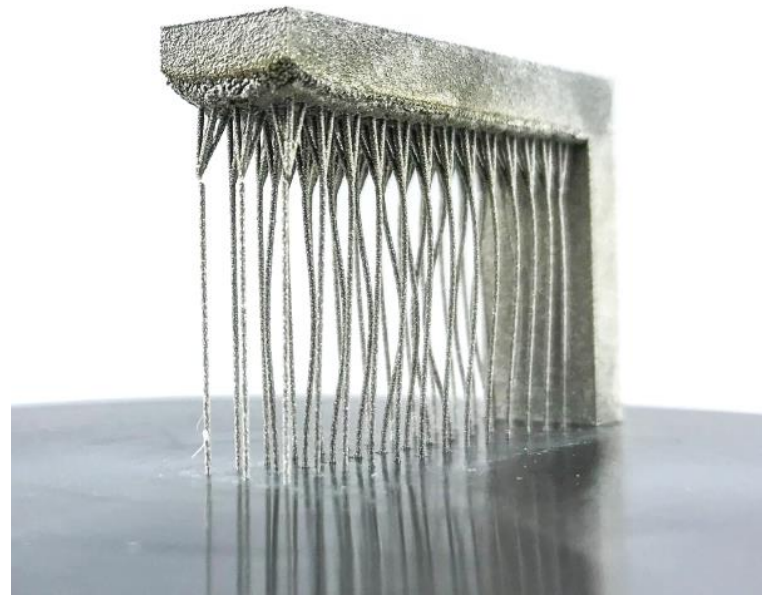

(a)

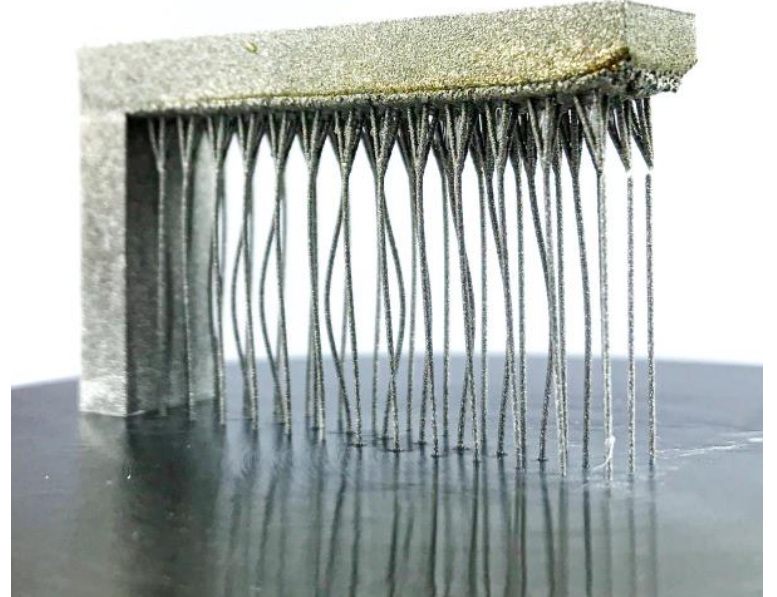

(b)

Figure 6. Failed support structure: Tree-like-Support with $0.4 \mathrm{~mm}$ stem diameter that failed during the build viewed from back (a) and front side (b)

\subsection{Conclusions, outlook and future work}

Support structure has a large impact on the printability of metallic parts. In addition, a proper support design might shorten the time needed for post-processing. Due to these aspects, support structure design needs to be addresses with the same relevance as part design within the DfAM field. The effects on build properties due to variation of machine parameters were determined based on a literature study. The results were visualized using arrows pointing in discrete directions from upwards to downwards. Additionally the list of investigated parameters under investigation was extended to design parameters for Tree-like support structures and evaluated based on experiences. Scanning speed and laser power showed to be the most influencing machine parameters within a controlled environment. For design parameters the stem and branch diameter as well as the number of branches were rated to affect the build properties the most. To see correlation effects between the build properties themselves, a third matrix was derived. It showed that especially support strength and printability are strongly correlated. Additionally to the build properties, scanning speed and laser power were added to the correlation matrix, as they are parameters of high importance. Finally, the results of the three matrices were utilized in a plan for experimental procedures. Control and noise factors, a response and the amount of levels per factor were identified. Based on these boundary conditions, the Taguchi Design approach L8 was chosen as a Design of Experiment tool. Future publications of the authors will present the proposed experimental procedures and verify the estimated effects of design parameters on build properties. Additionally to experiments, numerical simulations will be carried out to reduce the amount of necessary physical tests in the future. Further the investigation of more manufacturing parameters and their effect on support structures as well as design parameters for different support structure types could be addressed. Only when significant 
design parameters are determined and practical values for each parameter are found, the results should be extracted to complex geometries and checked for their applicability in those cases.

\section{References}

Bartsch, K. et al. (2019), "A Novel Approach to Support Structures Optimized for Heat Dissipation in SLM by Combining Process Simulation with Topology Optimization”, NAFEMS World Congress, Vol. 2019, p. 25.

Calignano, F. (2014), "Design optimization of supports for overhanging structures in aluminum and titanium alloys by selective laser melting", Materials \& Design, Vol. 64, pp. 203-213.

DIN (2017). DIN EN ISO/ASTM 52900:2017-06, Additive Fertigung- Grundlagen- Terminologie (ISO/ASTM 52900:2015); Deutsche Fassung EN ISO/ASTM 52900:2017, Beuth Verlag GmbH, available at: https://doi.org/10.31030/2631641

Domagala, T. (2018). "Increase productivity in the Metal 3D Printing industry", presented at the $3 D$ Valley Conference, Aachen, 26 September, available at: https://3d-valley.com/event-materials/Tim_Domagala_ Materialise.pdf (accessed 29 October 2019).

Dordlofva, C. and Törlind, P. (2018). "Design for Qualification: A Process for Developing Additive Manufacturing Components for Critical Systems", p. 10.

Gibson, I. (2017), "The changing face of additive manufacturing", Journal of Manufacturing Technology Management, Vol. 28 No. 1, pp. 10-17.

Hussein, A. et al. (2013), "Advanced lattice support structures for metal additive manufacturing", Journal of Materials Processing Technology, Vol. 213 No. 7, pp. 1019-1026.

Jiang, J., Xu, X. and Stringer, J. (2018), “Support Structures for Additive Manufacturing: A Review”, Journal of Manufacturing and Materials Processing, Vol. 2 No. 4, p. 64.

Kuo, Y.-H. et al. (2018), "Support structure design in additive manufacturing based on topology optimization", Structural and Multidisciplinary Optimization, Vol. 57 No. 1, pp. 183-195.

Mercelis, P. and Kruth, J. (2006), "Residual stresses in selective laser sintering and selective laser melting", Rapid Prototyping Journal, Vol. 12 No. 5, pp. 254-265.

Montero, J. et al. (2019), "Spare part production in remote locations through Additive Manufacturing enhanced by agile development principles", 2019 IEEE International Conference on Engineering. Technology and Innovation (ICE/ITMC).

Schleifenbaum, J.H. et al. (2019), "Future AM: Die nächste Generation additiver Fertigungsverfahren", In: Neugebauer, R. (Ed.), Biologische Transformation, Springer Berlin Heidelberg, Berlin, Heidelberg, pp. 229-250.

Strano, G. et al. (2013), "A new approach to the design and optimisation of support structures in additive manufacturing", The International Journal of Advanced Manufacturing Technology, Vol. 66 No. 9, pp. 12471254.

VDI (2014). VDI 3405, Additive Fertigungsverfahren - Grundlagen, Begriffe, Verfahrensbeschreibungen, Verein Deutscher Ingenieure e.V.

Wohlers, T. (2019). Wohlers Report 2019: 3D Printing and Additive Manufacturing State of the Industry.

Zhang, K. et al. (2018), "Study on the Geometric Design of Supports for Overhanging Structures Fabricated by Selective Laser Melting", Materials, Vol. 12, p. 1, available at:https://doi.org/10.3390/ma12010027 


\section{Appendix A}

\begin{tabular}{|c|c|c|c|c|c|c|c|c|c|c|}
\hline & & & 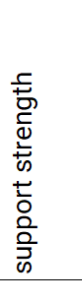 & & 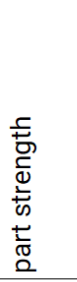 & 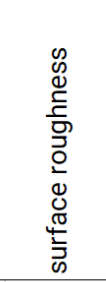 & 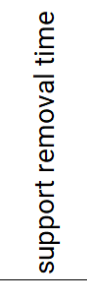 & 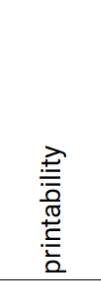 & 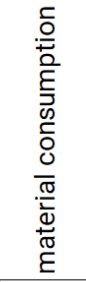 & 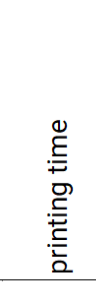 \\
\hline \multirow{9}{*}{ 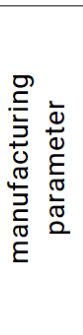 } & \multirow{9}{*}{$\begin{array}{l}\text { laser power } \\
\text { scanning speed } \\
\text { layer height } \\
\text { hatch spacing } \\
\text { hatch angle interval } \\
\text { baseplate temperature } \\
\text { build chamber temperature } \\
\text { gas flow improvement } \\
\text { layer skipping for supports }\end{array}$} & A & {$[1,2]$} & $M$ & {$[1,2]$} & $\forall[1,2]$ & $2[*]$ & $y$ [3] & 2 $1 *]$ & $\Rightarrow[4]$ \\
\hline & & 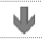 & {$[1,2]$} & $\varphi$ & {$[1,2]$} & A $[1,2]$ & $y[*]$ & $y$ [5] & $\Rightarrow[*]$ & $\psi[6]$ \\
\hline & & $\Rightarrow$ & {$[7]$} & $\Rightarrow$ & {$[7]$} & ค [8] & $?$ & y $[9]$ & $?$ & $\sqrt{W}[10$ \\
\hline & & ว & {$[11]$} & 27 & [11] & ภ [11] & $?$ & $?$ & $?$ & บ $[12$ \\
\hline & & ริ & {$[7]$} & 가 & [7] & $?$ & ? & $y[13]$ & $?$ & $\Rightarrow[*]$ \\
\hline & & ว & [14] & 2 & [14] & $y[15]$ & $?$ & ว $[15]$ & $?$ & $?$ \\
\hline & & 21 & [14] & 2 & [14] & y & $?$ & 2 $[15]$ & $?$ & $?$ \\
\hline & & & [16] & ᄀ & [16] & $y[16]$ & $?$ & ᄀ & $\Rightarrow[*]$ & $\Rightarrow[*]$ \\
\hline & & $\Downarrow$ & & $\Rightarrow$ & {$[\star]$} & $\Rightarrow[*]$ & $\forall[*]$ & $y[*]$ & $?$ & $y[*]$ \\
\hline
\end{tabular}

Figure 7. Matrix of Figure 3 including references

[1] D. Gu and Y. Shen, (Dec. 2008), "Processing conditions and microstructural features of porous 316L stainless steel components by DMLS," Applied Surface Science, Vol. 255 No. 5, pp. 1880-1887.

[2] N. Kaufmann et al. (2016), "Influence of Process Parameters on the Quality of Aluminium Alloy EN AW 7075 Using Selective Laser Melting (SLM)," Physics Procedia, Vol. 83, pp. 918-926.

[3] S. Kleszczynski et al. (2014), "Improving Process Stability of Laser Beam Melting Systems," presented at the Fraunhofer Direct Digital Manufacturing Conference (DDMC), Berlin, p. 7.

[4] M. Brandt, (2017), "The role of lasers in additive manufacturing," in Laser Additive Manufacturing, M. Brandt, (Ed.) Woodhead Publishing, pp. 1-18.

[5] I. Yadroitsev, Ph. Bertrand, and I. Smurov, (Jul. 2007), "Parametric analysis of the selective laser melting process," Applied Surface Science, Vol. 253 No. 19, pp. 8064-8069.

[6] M. Badrossamay et al. (2009), "Improving Productivity Rate in SLM of Commercial Steel Powders," in Technical Paper - Society of Manufacturing Engineers, Vol. 17.

[7] K. Guan et al. (Sep. 2013), "Effects of processing parameters on tensile properties of selective laser melted 304 stainless steel," Materials \& Design, Vol. 50, pp. 581-586.

[8] M. M. Savalani and J. M. Pizarro, (Jan. 2016), "Effect of preheat and layer thickness on selective laser melting (SLM) of magnesium," Rapid Prototyping Journal, Vol. 22 No. 1, pp. 115-122.

[9] T. Mukherjee et al. (Jan. 2016), "Printability of alloys for additive manufacturing," Scientific Reports, Vol. 6, p. 19717.

[10] M. Ma et al. (2015), "Layer thickness dependence of performance in high-power selective laser melting of 1Cr18Ni9Ti stainless steel," Journal of Materials Processing Technology, Vol. 215.

[11] M. Xia et al. (Oct. 2016), "Influence of hatch spacing on heat and mass transfer, thermodynamics and laser processability during additive manufacturing of Inconel 718 alloy," International Journal of Machine Tools and Manufacture, Vol. 109, pp. 147-157.

[12]Z. Dong et al. (2019), "Effect of Hatch Spacing on Melt Pool and As-built Quality During Selective Laser Melting of Stainless Steel: Modeling and Experimental Approaches," Materials, Vol. 12.

[13] J. H. Robinson et al. (2019), "The effect of hatch angle rotation on parts manufactured using selective laser melting," Rapid Prototyping Journal, Vol. 25.

[14]R. Mertens et al. (Jan. 2016), "Influence of Powder Bed Preheating on Microstructure and Mechanical Properties of H13 Tool Steel SLM Parts," Physics Procedia, Vol. 83, pp. 882-890.

[15] M. F. Zaeh and M. Ott, (Jan. 2011), "Investigations on heat regulation of additive manufacturing processes for metal structures," CIRP Annals, Vol. 60 No. 1, pp. 259-262.

[16]B. Ferrar et al. (Feb. 2012), "Gas flow effects on selective laser melting (SLM) manufacturing performance," Journal of Materials Processing Technology, Vol. 212 No. 2, pp. 355-364.

[*] common knowledge or based on experiences 